\title{
DONALD CAMPBELL: THE ACCIDENTAL EVALUATOR
}

\author{
William R. Shadish and Jason K. Luellen
}

\section{CAMPBELL'S EVALUATION POINT OF VIEW}

Donald T. Campbell passed away in 1996, but given his central importance to the field of evaluation, representing him in this book seems almost essential, so we have been asked to write this chapter about him in his place. Though we have more than passing familiarity with Campbell and his ideas (Shadish, Cook, \& Campbell, 2002; Shadish, Cook, \& Leviton, 1991), our reconstruction in this chapter may be as debatable as it is accurate, especially on personal matters in the last section, so we encourage additions and corrections to what we write below.

Campbell took on many roles throughout his 40-year intellectual career: social psychologist, social science methodologist, philosopher of science, sociologist of science, and evaluator. Yet underlying all this apparent diversity, the central theme of Campbell's work was describing, explaining, and improving how humans, including scientists, learn about the real world; and he was particularly interested in understanding and controlling both substantive and methodological biases. His substantive work is less well-known among evaluators, but it included bias in visual illusions, lines of communication, and especially social attitudes (Campbell, 1981). 
Most evaluators are more familiar with Campbell's work on methods, with factors that bias the collection, analysis, and interpretation of social data. Most prominently, he proposed a validity typology (Campbell, 1957; Campbell \& Stanley, 1963) that introduced the concepts of internal validity and external validity, outlined experimental and quasi-experimental research designs, and advocated ruling out threats to internal validity, such as selection, history, and maturation, using experimental methods. He preferred the use of random assignment to treatments, but he encouraged the use of quasi-experiments when that was all the situation allowed. The quasi-experimental design options offered by Campbell and Stanley (1963) empowered practicing researchers to test causal hypotheses in less-than-ideal field settings. Campbell's validity typology evolved over the years (Cook \& Campbell, 1979; Shadish et al., 2002), and the language he introduced persists to this day.

The profession of evaluation came to know Campbell through this methodological work: "Suchman's 1967 founding book on evaluative research cited my 'experimental and quasi-experimental designs' as the appropriate methodological mode, I thus became overnight both a senior program evaluator by fiat" (Campbell, 1984b, p. 13). Thus, Campbell's induction to the profession of evaluation was as much by accident as by his own design. Nevertheless, Campbell and Stanley (1963) has been rated among the most influential evaluation works (Shadish \& Epstein, 1987). Campbell wrote several other influential papers linked to evaluation, including "Reforms as Experiments" (1969), "Methods for the Experimenting Society" (1971), and "Qualitative Knowing in Action Research" (1978). His "Experimenting Society," an early intellectual vision of the role of evaluation in society, proposed a society committed to identifying effective reforms suitable for broad implementation. His writing on evaluation so centered on hypotheses about cause and effect that he came to represent the experimental approach to evaluation. Campbell never said that all evaluation should be solely concerned with causal questions and experimental methods, but he clearly viewed other methods as subordinate to experimentally based knowledge.

In much of the field of evaluation, however, Campbell's writings about methods are viewed in isolation, with little awareness of the key conceptual background in his work that led him to his experimental preference. That background is best exhibited by his writings on evolutionary epistemology (Campbell, 1974, 1977), a term that he introduced. Evolutionary epistemology extends the Darwinian notion of biological evolution to cognitive mechanisms 
and ideas. Thus, the acquisition of knowledge was viewed as a process of generating and testing falsifiable hypotheses, and retaining those that solved the problems at issue. Experimental methods were the key to evaluating those solutions. His work on evolutionary epistemology spanned 40 years, bringing him into personal acquaintance with Karl Popper, Michael Polanyi, W.V. Quine, and Konrad Lorenz. The work is summarized in his William James Lectures at Harvard, which long lay unpublished because Quine (who was rarely enthusiastic about any work) liked but did not love the work, so Campbell kept revising.

His interest in the evolution of ideas led him beyond philosophy to the history and sociology of science, discovering some sources of validity and invalidity that lie in the social organization of science rather than in the mechanics of research design. He adopted Popper's stance that knowledge is facilitated through criticism, calling for a "disputatious community of scholars" (Campbell, 1984a, p. 44) whose intellectual debates would help evaluation to flourish, creating a field that takes from science its open system of criticism and support, and expose more biases. He preferred the simultaneous funding of multiple evaluations of a program from different perspectives.

Yet through all this, Campbell rejected the "anything goes" philosophy prominent in scholars, from philosophers such as Feyerabend to some qualitative sociologists, and he rejected the antiscience, antiquantitative turn that came to dominate some areas of scholarship. After all, in biological evolution, variations are evaluated by their survival value, and Campbell believed the same should be true in knowledge construction. By all means, he said, diversify and debate the nature of the critical standards to be applied in this process, but be critical. Though his advocacy of experimental methods led him to be branded a logical positivist among evaluators who did not know his corpus of works, it is clear he rejected that philosophy of science in favor of evolutionary epistemology, a weak relativist sociology of knowledge, and an appreciation for cultural relativism.

In the end, however, Campbell's experimental approach to evaluation became just one small part of the field. Critics challenged his Experimenting Society, particularly the notion that experimental methods were preferred for evaluation. They argued that experimental methods were insufficient to address social problems in a world where policy practice is entangled with politics, economy, and social pressures; questioned the importance of noncausal questions and nonexperimental methods; complained that experimentally based 
knowledge was not fully implemented in solving social problems; and pointed out limitations of experimental methods. Eventually, the field of evaluation rejected Campbell's Experimenting Society as too narrow and Utopian, preferring a broader vision of the role of evaluation. Even so, because bias remains a central problem for evaluation, the solutions Campbell offered will be his greatest legacy.

\section{CAMPBELL'S PLACEMENT ON THE EVALUATION THEORY TREE}

Alkin and Christie's theory tree incorporates a large array of diverse evaluation thinking in one fell swoop. As such, it could be a useful orienting device to general thinking in evaluation, especially for the novice who is just learning about the field. Alkin and Christie place Campbell on the methods branch of their theory tree, referring to him as a "methodologist who has influenced evaluation." This is an apt characterization given that Campbell's early methodological writings on experimental and quasi-experimental designs were appropriated by Suchman to be a paradigm for evaluation, despite the fact that Campbell did not originally have that intention. Though Campbell did discuss such matters as use and valuing, those discussions were secondary to his thinking on knowledge construction. So, if one is limited to choosing among the branches of the existing theory tree, Campbell belongs on the central methods branch.

However, two problems with the theory tree could be of concern, both of which bear on how Campbell and others are conceptualized on the tree. The first problem concerns the difference between categories versus concept analysis. As Alkin and Christie note at the start of their chapter, the kind of simple category system embodied in the tree risks overemphasizing some features of a theorist's work and underemphasizing other features. Alkin and Christie note, for example, how difficult it was for them to categorize both Stake and Fetterman, because their work covers elements from all three branches of the tree. We tend to prefer a framework for evaluation theory in which the components of the system (methods, values, and use, in the case of Alkin and Christie) are not categories into which a theorist is exclusively placed, but rather are concepts that are all used to critique both strengths and weaknesses in a theorist's works. For example, a conceptual analysis of how 
Campbell addressed use and valuing both illuminates his position in the field relative to other theorists and enriches our theory base by providing ways of thinking that are not well represented by other theorists.

However, accepting the basic structure of the theory tree on its own terms, a second problem concerns branches that are either incomplete or missing. The methods branch may be incomplete. In the system we used in Shadish et al. (1991), methodology was part of the larger topic of knowledge construction that included epistemology and ontology, topics that are missing in the theory tree. The loss is not trivial, for Campbell's advocacy of experimental methods cannot adequately be understood apart from his evolutionary epistemology and his sociology of knowledge construction. Those works address issues that are mostly ignored by other theorists on the methods branch. Such issues are crucial to evaluation theory and deserve more explicit attention on the tree.

Missing entirely from the tree is a theory of the evaluand-for example, of social programs in the case of program evaluation or of products in the case of product evaluation - that helps the evaluator to understand how change occurs in the evaluand (Shadish et al., 1991). Such a theory is central to Campbell's work in the form of his Experimenting Society. Even though the Experimenting Society was too Utopian for evaluation, evaluation theory needs to have a place to discuss and compare it with parallel theories that are implicit or explicit in other evaluation theories. Alkin and Christie occasionally acknowledge such issues in their treatment of Suchman, Rossi, and Weiss; but they leave those issues relatively undeveloped compared with the other three branches.

\section{PERSONAL INFLUENCES ON CAMPBELL'S CAREER}

Reconstructing personal influences on the intellectual career of another is a difficult and dangerous task, particularly when that person is no longer living to offer rebuttal. So, in preparing this section, we relied on Campbell's autobiographical commentary (Campbell, 1981) and on personal observations passed on to us by those who knew him at Northwestern University.

Reading about Campbell is inspirational to any young researcher worried about projects that are rejected, failed, unfinished, unpublished, or mistaken in retrospect. He was age 33 before his first publication. He published in unrefereed journals. Among his most highly cited works were his unpublished 
William James Lectures at Harvard on evolutionary epistemology and his also unpublished "Qualitative Knowing in Action Research." (He eventually did publish them in an edited book toward the end of his career.) He worked on a diverse array of research topics, which included Yurok tribal myths as projective test protocols, emotional judgments using Olive Oyl cartoons from the "Popeye" series in The New Yorker, social attitudes toward various ethnic groups (his dissertation), morale among submarine crews after World War II, and the relationship between hair length and hardheadedness.

Campbell tells us little about personal influences on his work before graduate school, save for passing comments on how his fundamentalist religious upbringing affected his work on human moral behavior, and on how his family encouraged children to discuss matters of intellect at home. We can infer some other influences through knowledge of Campbell's work, for example, the influence of Tolman on Campbell's understanding of academic leadership and his graduate exposure to Kurt Lewin's action research seminar. However, many sources suggest that a crucial influence on Campbell was his time on the faculty at University of Chicago, his second position after a brief stint at Ohio State University. He experienced the atmosphere at Chicago as repressive, with many young professors hired to compete for few tenured positions and where faculty were afraid to share or publish ideas lest they be found to be less than intellectual giants. After a few years, he left Chicago for Northwestern after being told of the low likelihood he would ever be tenured there. His Chicago experience led him to foster the opposite atmosphere at Northwestern, where people could speak their minds without fear of ridicule and could generate diverse ideas that might often be dead ends; where the intellectual culture was more important than the individual persons; and where the best work came from theory groups working together more than from individuals competing with each other. The weekly "Social Psychology Sack Lunch" epitomized this atmosphere, aiming to generate ideas that might lead to novel methods, many of which did not succeed as well as hoped (e.g., cross-lagged panel design) but some of which bore fruit (e.g., regression discontinuity).

His Chicago experience also led him to be generous and gentle with young scholars (though he speaks of giving priority to student coauthors even at Ohio State), both graduate students and young professors, encouraging them to disagree with him and focusing on the positives in their work more than on the negatives. This extended beyond the intellectual to the social relationships. 
He would frequently take young scholars out and pay for their meals. Campbell was loved for this supportive style, generating great loyalty to him as person and scholar.

One can see, then, that Campbell put his evolutionary epistemology into practice in his academic and social career. He was an intellectual Darwinist of the kind who believed in generating and spreading a very large number of ideas (akin to blind variations) in hopes that some of them would solve problems and be incorporated into the accepted canon. From his early diverse undergraduate coursework in genetics, anthropology, and sociology, he constantly exposed himself to a wide array of ideas from many different disciplines. For every successful work like Campbell and Stanley (1963) or Campbell and Fiske (1959), he produced many research projects that received little or no attention and that often were never published. He did his best to create an environment at Northwestern that encouraged such intellectual diversity, whether it be the Social Psychology Sack Lunch; interdisciplinary research groups that included philosophers, qualitative sociologists, and policy researchers as well as psychologists; or his mentoring of experimental psychology graduate students who were encouraged to take coursework in art, philosophy, and religion. In doing this, he left a legacy of intellectual creativity larger than himself, one that spread over fields as diverse as evaluation, philosophy, sociology, and psychology. His ideas, like any successful genetic variation, survive because we need them.

\section{REFERENCES}

Campbell, D. T. (1957). Factors relevant to the validity of experiments in social settings. Psychological Bulletin, 54, 297-312.

Campbell, D. T. (1969). Reforms as experiments. American Psychologist, 24, 409-429.

Campbell, D. T. (1971). Methods for the experimenting society. Paper presented to the Eastern Psychological Association, New York City, and to the American Psychological Association, Washington, DC.

Campbell, D. T. (1974). Evolutionary epistemology. In P. A. Schilpp (Ed.), The philosophy of Karl Popper. La Salle, IL: Open Court Publishing.

Campbell, D. T. (1977). Descriptive epistemology: Psychological, sociological, and evolutionary. William James Lectures, Harvard University.

Campbell, D. T. (1978). Qualitative knowing in action research. In M. Brenner, P. Marsh, \& M. Brenner (Eds.), The social context of methods (pp. 184-209). London: Croom Helm. 
Campbell, D. T. (1981). Comment: Another perspective on a scholarly career. In M. B. Brewer \& B. E. Collins (Eds.), Scientific inquiry and the social sciences (pp. 453-501). San Francisco: Jossey-Bass.

Campbell, D. T. (1984a). Can we be scientific in applied science? In R. F. Connor, D. G. Altman, \& C. Jackson (Eds.), Evaluation studies review annual (Vol. 9, pp. 26-48). Newbury Park, CA: Sage.

Campbell, D. T. (1984b). Hospital and landsting as continuously monitoring social polygrams: Advocacy and warning. In B. Cronholm \& L. von Knorring (Eds.), Evaluations of mental health service programs (pp. 13-39). Stockholm: Forskningsraadet Mediciniska.

Campbell, D. T., \& Fiske, D. W. (1959). Convergent and discriminant validation by the multitrait-multimethod matrix. Psychological Bulletin, 56, 81-105.

Campbell, D. T., \& Stanley, J. C. (1963). Experimental and quasi-experimental designs for research on teaching. In N. L. Gage (Ed.), Handbook of research on teaching (pp. 171-246). Chicago: Rand McNally.

Cook, T. D., \& Campbell, D. T. (1979). Quasi-experimentation: Design and analysis issues for field settings. Chicago: Rand-McNally.

Shadish, W. R., Cook, T. D., \& Campbell, D. T. (2002). Experimental and quasi-experimental designs for generalized causal inference. Boston: Houghton Mifflin.

Shadish, W. R., Cook, T. D., \& Leviton, L. C. (1991). Foundations of program evaluation: Theories of practice. Newbury Park, CA: Sage.

Shadish, W. R., \& Epstein, R. (1987). Patterns of program evaluation practice among members of Evaluation Research Society and Evaluation Network. Evaluation Review, 11, 555-590. 